\title{
ANÁLISE DA ATUAÇÃO DE FOTOJORNALISTAS \\ SOB UMA ABORDAGEM DE GENNERO: \\ O CASO DO PORTAL FOTOS PÚBLICAS*
}

\author{
Nathália Cunba da SILVA** \\ Pedro Henrique TOTH ${ }^{* * *}$ \\ Universidade Metodista de São Paulo, São Paulo, SP
}

RESUMO

Apesar de existir uma lacuna dos estudos de gênero dentro do fotojornalismo, é perceptível a concentração masculina nessa área, na contramão dos seus quadros textuais. Em busca de indícios sobre essa atuação no Brasil, o presente artigo realiza uma pesquisa exploratória sobre o único portal brasileiro de fotojornalismo que concentra imagens de divulgação gratuitas: o Portal Fotos Públicas. Para a construção da base de dados analisada, escolheram-se ferramentas computacionais que localizaram e capturaram os dados das galerias de imagem para o posterior cruzamento dos dados. Interpretaram-se os resultados a partir da obra A Dominação Masculina, de Pierre Bourdieu, divididos em três recortes principais: produção, agências e editorias.

Palavras-chave: Fotojornalismo; gênero; banco de imagens; fotos públicas.

\section{INTRODUCÃO}

A fotografia nasceu no ambiente positivista do século XIX, fruto de avanços científicos que ansiavam por encontrar um meio que permitisse a reprodução mecânica da realidade visual. Logo, a imprensa apropriou-se do caráter testemunhal da fotografia para conferir mais credibilidade às suas coberturas. A vocação noticiosa do fotojornalismo, entretanto, revelou-se durante a cobertura de guerras, conhecidas como a temática das primeiras

* Trabalho apresentado no GT Comunicação digital e tecnologias, do PENSACOM BRASIL 2016.

** Mestra em Comunicação Social pelo Programa de Pós-Graduação em Comunicação Social da Universidade Metodista de São Paulo, Bolsista Capes, e-mail: nathaliacunhasilva@gmail.com.

*** Mestre em Comunicação Social pelo Programa de Pós-Graduação em Comunicação Social da Universidade Metodista de São Paulo, e-mail: pedrototh@gmail.com. 
reportagens fotográficas publicadas. Com início em 1855, durante a Guerra da Crimeia, ainda com uma cobertura estática, o fotojornalismo ganhou agilidade somente após o término da Primeira Guerra Mundial, quando inovações técnicas iriam possibilitar novas formas de a imprensa utilizar a fotografia (SOUZA, 2004, p. 24 - 26).

Apesar da grande afinidade entre a ela e o fotojornalismo, relação que se mantém até os dias de hoje, a ocupação profissional dos quadros de cobertura textual e visual seguiram caminhos opostos. A pesquisa, realizada em âmbito nacional pela Federação Nacional dos Jornalistas (FENAJ), em conjunto com o Programa de Pós-Graduação em Sociologia Política da Universidade Federal de Santa Catarina (UFSC), aponta que 64\% dos jornalistas brasileiros eram mulheres, em 2012 (BERGAMO; MICK; LIMA, 2012, p. 7). Já outra pesquisa, pioneira no fotojornalismo mundial, intitulada The State of News Photography, estudou 1.556 fotógrafos, de mais de 100 países, e, entre eles, encontrou apenas cerca de 15\% de mulheres (HANDLAND, CAMPBELL, LAMBERT, 2015, p. 54).

A disparidade da atuação entre os gêneros, em áreas diferentes do jornalismo, dedicadas às coberturas textual e imagética, constitui o reflexo da estruturação histórica desses mercados, da consequente mudança nos modos de produzir e de consumir notícias, mas, sobretudo, dos diferentes valores sociais atribuídos à atuação profissional de homens e de mulheres. Como há uma lacuna nos estudos sobre a prática do fotojornalismo em geral e, consequentemente, menor ainda sob a perspectiva de gênero, foi escolhido, como objeto de análise, o site 'Fotos Públicas', por ser o único espaço brasileiro destinado a reunir imagens fotojornalísticas de divulgação gratuita, com política de uso regida pelo Creative Commons ${ }^{1}$. As imagens são provenientes de coberturas produzidas em âmbito nacional por entidades esportivas, culturais, políticas, ambientalistas e científicas; governos de todos os níveis e assessorias privadas. Os fotojornalistas responsáveis são remunerados por esses trabalhos e, dessa forma, não dependem financeiramente da venda das imagens como em agências de notícias, por exemplo.

Nesse contexto, este artigo realiza uma pesquisa exploratória, com base nos dados capturados a partir do portal Fotos Públicas, com o intuito de levantar indícios sobre a atuação dos fotojornalistas brasileiros nesse nicho de mercado. Para construir a base de dados, escolheram-se uma linguagem de programação e uma biblioteca de automatização, que localizaram e captura-

Dentro da licença Creative Commons é dada a liberdade para compartilhar e adaptar o material a qualquer suporte ou formato, para qualquer fim, mesmo que comercial, desde que se atribua o devido crédito, se proveja um link para a licença e se indique se mudanças foram feitas. <http://creativecommons. org/licenses/by/3.0/br/>. 
ram os dados das galerias de imagem. Posteriormente, filtraram-se os dados coletados, com o intuito de analisar somente as coberturas brasileiras e os créditos classificados pelo gênero ${ }^{2}$. Dividiram-se os resultados, obtidos a partir do cruzamento de dados, em três recortes principais: produção, agências e editorias. A análise do portal, de pouco mais de dois anos, encontrou 1.301 profissionais, entre eles 261 mulheres e 1.040 homens, que atuam, predominantemente, em agências públicas.

Quando se estuda qualquer recorte sob o olhar de gênero, é importante levar em consideração a necessidade de realizar uma abordagem multidisciplinar, pois, ao mesmo tempo em que os números são relevantes para evidenciar determinadas situações assimétricas entre os gêneros, eles não dão conta de explicar o caráter sócio-histórico e cultural a permear as relações de gênero. Então, para interpretar os resultados levantados, realizou-se uma análise à luz dos conceitos de gênero da obra A Dominação Masculina, de Pierre Bourdieu.

\section{DIVISÃO SEXUAL DOS PAPÉIS SEXUAIS}

As estruturas estabelecidas de gênero não são prejudiciais apenas para mulheres, mas para todos os que possuem corpos sexuados. Com efeito, o gênero corresponde a um manual de regras, instituído socialmente, que estabelece os códigos de atos e de características definidores de cada gênero. Dentro dessa lógica, os conceitos de sexo e de gênero não devem ser entendidos como diferentes, pois ambos constituem leituras culturais encadeadas. Segundo o livro A Dominação Masculina, do sociólogo francês Pierre Bourdieu (2014, p. 27-28), a visão que institui o sexo como natural, enquanto o gênero, como sua interpretação cultural, é utilizada para impor, como neutra, a lógica androcêntrica. Isso porque, se o sexo é compreendido apenas como a descrição da "[...] diferença anatômica entre os órgãos sexuais, pode assim ser vista como justificativa natural da diferença socialmente construída entre os gêneros e, principalmente, da divisão social do trabalho" (BOURDIEU, 2014, p. 25).

$\mathrm{O}$ autor defende que a dominação masculina e o modo como é imposta e vivenciada resulta de uma violência simbólica. Em sua definição, a violência simbólica seria aquela "[...] violência suave, insensível a suas próprias vítimas, que se exerce essencialmente pelas vias puramente simbólicas da comunicação e do conhecimento, ou, mais precisamente, do desconhecimento, do reconhecimento ou, em última instância, do sentimento" (BOURDIEU, 2014, p. 12). Em adição, o simbólico não deve ser entendido como irreal, ou puramente espiritual, porque suas consequências existem. Assim, a subjetividade nas relações

Neste artigo, trabalhamos com o entendimento restrito de gênero como dividido entre masculino e feminino. 
de dominação não se encontra desprovida de objetividade, porque sua intenção consiste em manter os privilégios atribuídos às atividades, às características e a todos os ideais simbólicos masculinos, como a virilidade e a objetividade.

Sobre essa questão, Bourdieu (2014, p. 86) defende que a própria noção de vocação profissional se vincula ao sistema simbólico, que busca combinar os espaços sexuados, a partir de suas tarefas, com o estereótipo de gênero cultural a ela atribuído. As "expectativas objetivas" de cada profissão estariam inscritas, implicitamente, nas carreiras oferecidas às mulheres, segundo as definições que a estrutura reserva para as "disposições ditas femininas". Tais "disposições" são reproduzidas também pela família e por toda a ordem social. Nesse sentido, optar por seguir os caminhos conformados ao seu gênero pode funcionar como fonte de recompensas. Tal situação contribui para reforçar a "dicotomia sexual fundamental, tanto nos cargos, que parecem exigir a submissão e a necessidade de segurança, quanto em seus ocupantes identificados com posições nas quais, encantados ou alienados, eles simultaneamente se encontram e se perdem" (BOURDIEU, 2014, p. 86).

Para Walter Lippmann (2008), os estereótipos seriam imagens mentais que auxiliam os indivíduos a compreender-se e a situar-se no mundo, a partir da sua inscrição social. Um mundo que oferece o conforto daquilo que é familiar ao indivíduo, que reúne e ajusta suas esperanças. Qualquer inconformidade causaria um abalo em suas estruturas. Admite-se, claramente, assim, que nenhum estereótipo é neutro, "são as fortalezas da nossa tradição e, atrás de nossas defesas, podemos continuar a sentir-nos seguros na posição que ocupamos" (LIPPIMANN, 2008, p. 97).

A divisão do trabalho pode ser entendida como a distribuição bastante estrita das atividades atribuídas a cada um dos dois sexos, o que ratifica, a partir do funcionamento da ordem social, a dominação masculina na qual se alicerça. O pleno exercício do privilégio, "concedido aos homens", afirma-se "na objetividade de estruturas sociais e de atividades produtivas e reprodutivas, baseadas em uma divisão sexual do trabalho de produção e reprodução biológica e social, que confere, aos homens, a melhor parte, bem como nos esquemas imanentes a todos os habitus [...]" (BOURDIEU, 2014, p. 54, grifo do autor). A ideia de habitus liga-se ao ideal de uma lei social incorporada, especialmente, como visto, por meio da prática reiterada das disciplinas atribuídas ao corpo e das matrizes de percepção, de atribuição de valores e de pensamentos e ações, reforçadas pelos diversos agentes sociais. A força da ordem masculina evidencia-se no fato de que ela dispensa justificação, uma vez que a visão androcêntrica se impõe como neutra.

Distante do determinismo, as identidades de gênero, construídas socialmente, oferecem um conjunto de características que, dentro da sistemática 
androcêntrica, se aproximam mais de determinados cargos e profissões, ao mesmo tempo em que se afastam de outras. E, pelos mesmos mecanismos de "naturalização" de gênero, a afinidade com determinadas carreiras, entendida como vocação, parece ser mais evidente a um gênero que ao outro. Assim, os estereótipos de gênero, de tão naturalizados na dinâmica social, são mais facilmente explicitados por meio de levantamentos que comparam a distintiva ocupação de homens e de mulheres por carreira, como será discutido mais adiante.

\section{CAPTURA DE DADOS}

Para a construção da base de dados utilizada neste projeto, o primeiro passo, logo após a seleção do site, constituiu um estudo apurado na estrutura do website. Nesse estudo inicial, analisou-se toda a estrutura do código HTML $^{3}$, e levantaram-se todos os padrões de codificação presentes na página. Tal análise mostrou-se fundamental pois, como o objeto de estudo constitui um website de médio porte, não possui nenhum tipo de $\mathrm{API}^{4}$ que impossibilitasse qualquer tipo de extração de dados automatizada.

Depois de conhecer a estrutura do objeto de estudo, a segunda etapa consistiu na seleção do método de extração de dados. Para realizar a tarefa, fizeram-se duas escolhas: a linguagem de programação Perl $^{5}$ e a biblioteca de automatização, chamada WWW-Mechanize ${ }^{6}$. Escolheu-se a linguagem Perl pois é simples de programar, open source e também porque não demanda um hardware de alta capacidade para seu processamento. Já a escolha da biblioteca WWW-Mechanize justifica-se por consolidar, em si, diversas outras bibliotecas de programação de funções parecidas com a sua, ou seja, ao invés de se trabalhar com diversas outras bibliotecas, pode-se fazer o uso de somente uma, que atuará como um canivete suíço.

Com as ferramentas escolhidas, construiu-se um script capaz de entrar no site e de encontrar todas as páginas de publicações das editorias. O resultado do processamento desse script foi um arquivo de texto contendo 17.565 hyperlinks. Esses hyperlinks compreendem todas as postagens presentes nas editorias do site, como ciência, cotidiano, cultura, economia, educação, entretenimento, esportes, mundo, negócios, polícia, política, saúde, segurança, tecnologia e turismo. O período de captura ocorreu de 26 agosto de 2013, data de criação do site, até 30 de outubro de 2015.

\footnotetext{
HyperText Markup Language - Linguagem de Marcação de Hipertexto

Application Programming Interface - Interface de Programação de Aplicação

https://www.perl.org/

http://search.cpan.org/ ether/WWW-Mechanize-1.75/lib/WWW/Mechanize.pm
} 
De posse de todos os hyperlinks, a terceira etapa do projeto consistiu em montar um segundo script, responsável por ler o arquivo com todos os hyperlinks e por navegar em cada uma das ocorrências lá existentes. Ao acessar o hyperlink, o script capturou dados relevantes da galeria de imagem, como título da galeria, data da postagem, hora da postagem, editoria e, por fim, crédito do fotógrafo e respectiva agência.

\section{TRATAMENTO DE DADOS}

A partir dos dados coletados, descartaram-se as agências internacionais para que a pesquisa se centrasse na observação da produção brasileira. Após esse processo de filtragem dos dados, restaram 13.175 links, do total inicial de 17.565, uma amostra ainda representativa, que abarcou mais de dois anos de existência do portal Fotos Públicas (entre agosto de 2013 e outubro de 2015).

Cada hiperlink corresponde ao endereço eletrônico de uma galeria de fotos (não se contabilizou, neste estudo, a quantidade de fotos presentes). Levaram-se em conta as informações contidas nessa galeria, como crédito do fotógrafo, agência, editoria, título da galeria e data. Isso posto, teve início o cruzamento de dados em si, cujos resultados serão descritos adiante, divididos em três recortes principais: produção, agências e editorias.

\section{CENÁRIO GERAL DE PRODUÇÃO}

A análise dos dados capturados demonstrou uma produção de 13.175 galerias, cada uma dedicada à cobertura de uma pauta com editoria específica, crédito, agência e data. Nesse recorte, encontrou-se um total de 1.301 profissionais, sendo 261 mulheres e 1.040 homens. Como o site entrou no ar em agosto de 2013 e a captura aconteceu até outubro de 2015, adotamos um recorte que abrange o período simétrico de 12 meses para comparar como se distribui a produção de ambos os sexos ao longo dos anos, conforme mostra a tabela 1. A opção por não iniciar a contagem a partir do mês de agosto de 2013, mas em outubro, ocorreu para minimizar o efeito gerado pela baixa produção logo no primeiro mês do portal e, ainda, conseguir explorar o ponto mais atual da amostra.

Tabela 1 - Acumulado de produção

\begin{tabular}{|c|c|c|c|c|}
\hline $\begin{array}{l}\text { Acumulado } \\
\text { Profissionais }\end{array}$ & $\begin{array}{l}0,4 / 13 \text { aे } \\
0 u t / 14\end{array}$ & $\begin{array}{l}\text { Out/14 aे } \\
\text { Out/15 }\end{array}$ & Variasso & staters \\
\hline $\begin{array}{l}\text { Mulneres } \\
\text { Momens }\end{array}$ & $\begin{array}{r}307 \\
1.561 \\
\end{array}$ & 2.064 & $\begin{array}{l}18,6 \% \\
28,3 \%\end{array}$ & $\hat{A}$ \\
\hline $\begin{array}{l}\text { Acumulado } \\
\text { produsalo }\end{array}$ & $\begin{array}{l}0 u t / 13 \text { aे } \\
\text { Out/14 }\end{array}$ & $\begin{array}{l}0 m / 14 \text { aे } \\
\text { out/15 }\end{array}$ & Variasao & staters \\
\hline $\begin{array}{l}\text { Muineres } \\
\text { Homens }\end{array}$ & 4. 701 & $\begin{array}{r}996 \\
6.886\end{array}$ & $\begin{array}{l}42,1 \% \\
44,7 \%\end{array}$ & 든 \\
\hline Produtividade & $\begin{array}{l}\text { Out/13 à } \\
0 u t / 14\end{array}$ & $\begin{array}{l}\text { Out/14 a } \\
\text { out/15 }\end{array}$ & Variasao & staters \\
\hline $\begin{array}{l}\text { Mulneres } \\
\text { Momens }\end{array}$ & $\begin{array}{l}2,28 \\
3,05\end{array}$ & $\begin{array}{l}2,74 \\
3,44\end{array}$ & $\begin{array}{l}19,8 \% \\
12,8 \%\end{array}$ & - \\
\hline
\end{tabular}

Fonte: Elaborado pelos autores. 
O recorte sugere que, ao longo de dois anos, aumentou a produção, tanto a masculina, quanto a feminina. Em outras palavras, apesar de a quantidade de pautas produzidas por homens ser preponderante, a variação de crescimento da produção, de ambos os sexos, quase se equipara. Há ênfase especial ao aumento da parcela masculina, que domina a cobertura, o que indica a concretização da tendência internacional, apontada pelo estudo The State of News Photography, também nesse nicho de mercado brasileiro.

\section{AS AGÊENIAS}

O portal Fotos Públicas contempla grande variedade de agências. Em 2013, reunia 99 e, em outubro de 2015, já contava com 294. No entanto a produção das agências é extremamente concentrada: apenas 18 agências detêm $70 \%$ da produção total. O gráfico abaixo ilustra essa distribuição.

Figura 1 - Agências mais relevantes

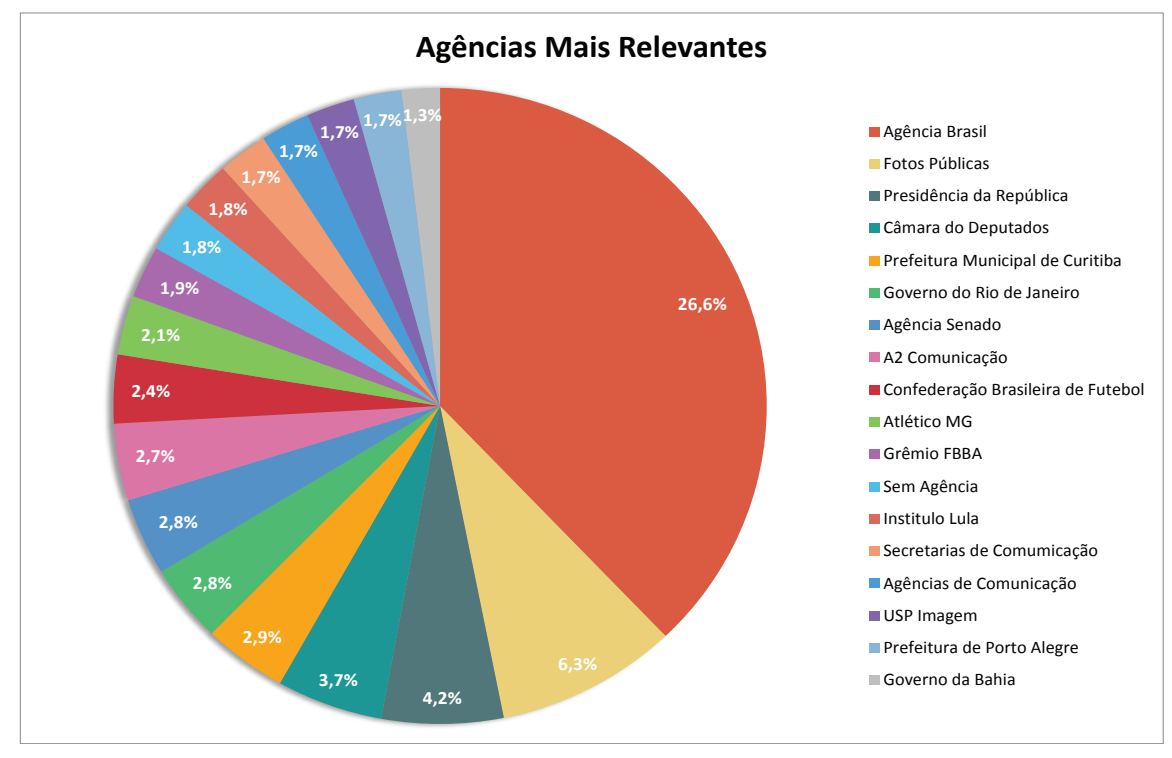

Fonte: Elaborado pelos autores.

A análise da figura 1 sugere a maior participação de instituições vinculadas ao governo em suas diversas instâncias - federal, estadual e municipal, ministérios, câmaras, assembleias, secretarias de comunicação, entre outras. Segundo o levantamento, $23 \%$ do total de profissionais atuam na comunica- 
ção de alguma instituição pública ${ }^{7}$ e, dentro desse recorte, $72 \%$ são homens, enquanto $28 \%$, mulheres.

Um dos exemplos mais significativos consiste no caso da Agência Brasil ${ }^{8}$, que, sozinha, é responsável por $26,6 \%$ da cobertura total de pautas, o que a deixa na liderança absoluta de produtividade dentro do site. A parceria com a agência aconteceu desde o início do portal Fotos Públicas, o que contribui para o entendimento da sua representatividade. Foram identificados 44 profissionais vinculados à agência, dos quais, 16 mulheres e 28 homens, o que também a coloca na liderança de contratação de profissionais do sexo feminino. Entretanto não é possível afirmar, somente com a observação dos dados coletados, se esses vínculos dos profissionais com as agências são formais ou informais.

Uma tentativa de entender o cenário de oportunidades de atuação entre os sexos está representada no gráfico abaixo, no qual foi possível dividir a atuação de homens e de mulheres de acordo com a quantidade de agências em que atuam.

Figura 2 - Atuação de profissionais por agências
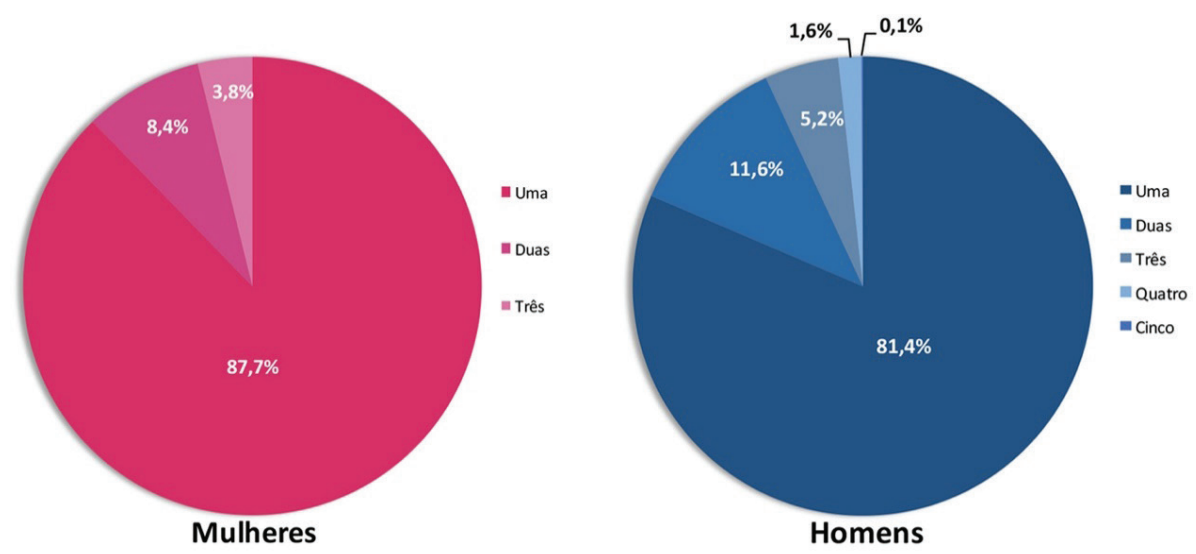

Fonte: Elaborado pelos autores.

7 Neste caso, não fazemos a distinção entre comunicação pública e governamental, as duas entendidas como vinculadas ao governo, principalmente por ambas se manterem, total ou parcialmente, por recursos públicos.

8 A Agência Brasil pertence à Empresa Brasil de Comunicação (EBC), criada em 2007, empresa pública que faz a gestão da TV Brasil, TV Brasil Internacional, Agência Brasil, Portal EBC, Radioagência Nacional e do sistema público de Rádio - composto por oito emissoras. Fonte: <http://www.ebc.com.br/>. 
Segundo a figura 2, os homens possuem maior versatilidade nas oportunidades de atuação em mais de uma agência, podendo chegar a, no máximo, cinco para um mesmo profissional; as mulheres chegam ao limite de três oportunidades de atuação para cada profissional. Mas, no geral, o cenário demonstra a tendência à forte concentração do trabalho em apenas uma agência: homens e mulheres cobrem pautas para uma mesma agência em mais de $80 \%$ dos casos.

Ainda sobre as oportunidades de trabalho, percebeu-se que apenas 21 mulheres, do total de 261, atuam em 23 agências e respondem por $70 \%$ da produção total feminina. Por outro lado, para atingir $70 \%$ da produção total dos homens, são necessários 76 profissionais de um total de 1.040, distribuídos em 63 agências. Adicionalmente, no período, observou-se que apenas duas profissionais, pertencentes à Agência Brasil, são responsáveis por 34,5\% da produção total das mulheres. Os números sugerem, além de reforçar a importância dessa agência, que poucas mulheres inseridas no meio são responsáveis por elevado volume de trabalho, fato indicativo de que poucas fotojornalistas conseguem ser, efetivamente, ativas na carreira, enquanto as demais aparecem esporadicamente, ao longo do tempo.

\section{AS EDITORIAS}

O portal dispõe, atualmente, de 15 editorias fixas. Cada uma possui uma fatia de relevância no que diz respeito à cobertura geral: Cotidiano, com 31,3\%, Política, com 30,6\%, as duas de maior representatividade; Esportes, com 14,8\%, Cultura, com 8\%, Economia, com 5,1\%, Saúde, com 2,6\%, Mundo, com 1,9\%, Entretenimento, com 1,4\%, Educação, com 1,3\%, Polícia, 1,1\%, Tecnologia, com $0,8 \%$, Turismo, com $0,7 \%$, Segurança, com 0,2\%, Negócios, com 0,2\% e Ciência, com 0,05\%. Três dessas editorias foram acrescentadas ao longo do tempo, já que Segurança e Polícia surgiram em 2014, com o aumento da visibilidade das áreas devido à Copa do Mundo e às Eleições; e Ciência, em 2015.

Tais fatos ajudam a compreender as editorias em que há uma maior quantidade de coberturas realizadas por mulheres, mas, ainda, em menor proporção que a produção masculina: Segurança, com 24,1\%, Saúde, com 21,4\%, Tecnologia, com 19,3\% e Cultura, com 18,9\%. Juntas, as editorias apontadas representam apenas $11,6 \%$ da produção total do portal. Comparativamente, as editorias com maior quantidade de coberturas masculinas são Esportes, com 95,3\%, Mundo, com 91,8\%, Política, 91,1\%, e Economia, com 90,6\%. Tais editorias reúnem mais da metade do conteúdo total do período, 52,3\%, o que angaria não somente mais atenção, mas também as aponta como as mais relevantes no cenário. A única exceção constitui a editoria de Cotidia- 
no, com 31,30\%, e que distribui sua cobertura em $81,8 \%$ para os homens, e 18,2\%, para as mulheres. Logo, os homens não só são maioria em relação às mulheres, correspondendo a $79 \%$ do total de profissionais, mas também atuam, predominantemente, em editorias de maior representatividade. Eles ainda concentram maior volume proporcional de cobertura em todas as editorias.

Já a distribuição interna das editorias entre os profissionais de cada gênero está representada na figura 3. Nela, é possível verificar que as editorias de Cotidiano e de Política são representativas nas coberturas de homens e mulheres, e, juntas, correspondem a $61,9 \%$ do conteúdo do portal. Como $23 \%$ do total de profissionais atua na comunicação de alguma instituição pública, a ênfase em Política parece natural, e Cotidiano concentra assuntos de interesse mais geral, sendo facilmente preenchida. Entre os homens, a editoria de Política aparece em primeiro lugar em volume de cobertura, em pelo menos dois anos, seguida de Cotidiano, a mais relevante em 2014; Esportes fica estacionada em terceiro lugar em representatividade ao longo do tempo. Em relação às mulheres, os homens variam pouco a sua participação dentro das editorias.

Figura 3 - Distribuição das Editorias por gênero

Editorias por Sexo

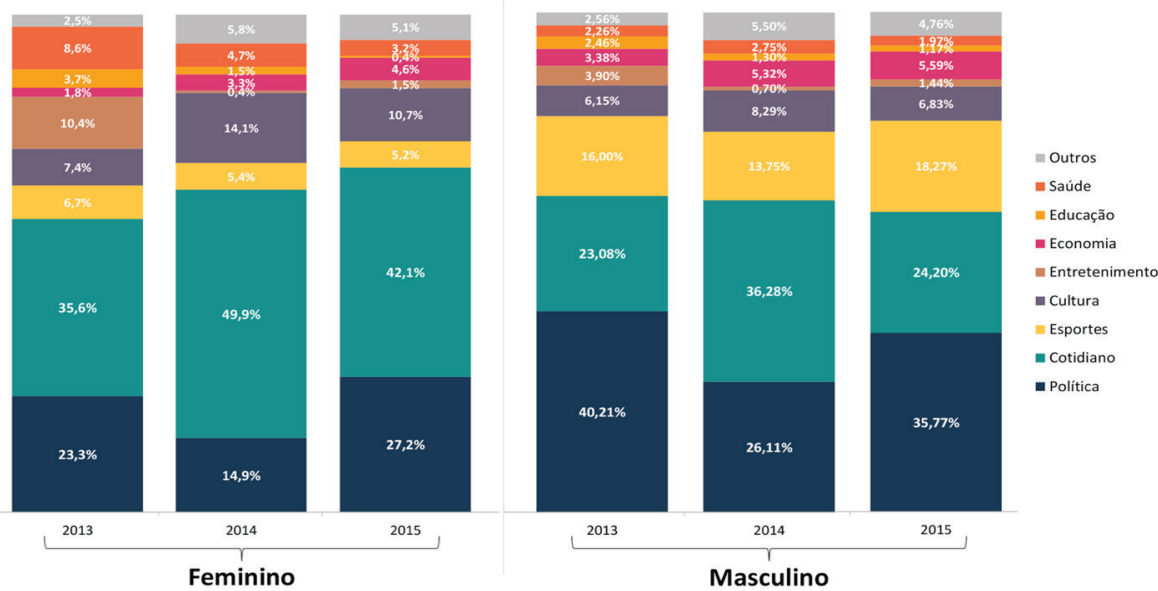

Fonte: Elaborado pelos autores.

No âmbito da divisão interna das mulheres entre as editorias, há também um consenso no foco da cobertura de Cotidiano e de Política, respectivamente, e Cultura aumenta sua participação a partir de 2014. Houve perceptível queda para ambos os sexos na cobertura de Saúde, de Educação e de 
Entretenimento. A editoria de Economia apresentou aumento significativo para ambos os sexos. Na formatação do gráfico, foram concentradas as editorias Mundo, Tecnologia, Turismo, Negócios, Política, Segurança e Ciência no tópico 'Outros'. Isso foi feito para melhorar a visualização do gráfico e concentrar editorias de pequena participação nesse caso.

Em um dos casos mais icônicos culturalmente, o volume de coberturas dentro da editoria de Esportes por mulheres aparece em último lugar, com apenas 4,7\%, ante 95,3\% dos homens. Mas, mesmo assim, a cobertura delas ocupa uma média de 5,8\% do total de trabalho feminino, índice superior ao de Segurança, que representa apenas $0,46 \%$ da cobertura total das mulheres. O contexto geral denota que, na editoria de Esportes, a concorrência com os homens é maior, ante o trabalho em Segurança, menos coberto. A participação feminina na editoria de Esportes é, historicamente, pequena, motivada, sobretudo, pelo lugar de destaque que o futebol ocupa na sociedade brasileira. Isso se soma ao fato de que o futebol e a maior parte das modalidades esportivas não têm o estereótipo da sua atividade associada à integração das mulheres, constituindo, assim, um ambiente esportivo que valoriza mais a participação masculina e é coberto, principalmente, por homens, com participações femininas apenas pontuais.

No geral, observar a ocupação das editorias indica que as mulheres, em minoria profissional numérica, tendem a apresentar uma maior proporção comparativa de coberturas dentro das editorias com menor concorrência masculina; ao mesmo tempo, possuem menor visibilidade e relevância de conteúdo geral. Em todas as editorias foram localizadas coberturas femininas, mesmo que em menor quantidade.

\section{FOTOJORNALISMO E DOMINAÇÃO MASCULINA}

Diante do quadro levantado, a atividade fotojornalística estudada, dentro do portal Fotos Públicas, reafirma a tendência internacional de concentração de homens dedicados à sua cobertura. O fato pode ligar-se à formação do estereótipo sobre a profissão, que despontou em um período de guerras, pois, até hoje, as coberturas imagéticas de protestos e de conflitos ganham maior notoriedade dentro do jornalismo. Delineia-se, desse modo, o fotojornalismo segundo um estereótipo de virilidade e de necessidade de domínio da vida e da via pública para o desenvolvimento da sua atuação.

Somente essas características, historicamente, já oferecem, de forma simbólica, um entrave à caracterização do fotojornalismo como atividade predisposta à ocupação feminina. Visto que, como explica Bourdieu: 
Ser 'feminina' é, essencialmente, evitar todas as propriedades e práticas que podem funcionar como sinais de virilidade; e dizer de uma mulher de poder que ela é 'muito feminina' não é mais que um modo particularmente sutil de negar-lhe qualquer direito a este atributo caracteristicamente masculino que é o poder (BOURDIEU, 2014, p. 138).

Ou seja, virilidade e poder mantêm uma relação simbólica muito próxima. A presença masculina ratifica a excelência da atividade, que imprime mais seriedade e dominância profissional para o reconhecimento de sua produção. Associa-se, aos homens, um exercício legítimo do poder, à medida que ele é, por definição, cunhado para ser o reflexo das características masculinas e, o feminino, a sua oposição direta e radical. A reflexão do autor auxilia na interpretação da dominação masculina na área do fotojornalismo, visto que a própria execução do trabalho por homens atribuiria maior credibilidade à cobertura, envolta no estereótipo masculino de objetividade, de seriedade e de maior comprometimento com a carreira, além da virilidade expressa.

Nesse sentido, os dados encontrados podem apontar uma dificuldade das mulheres em ingressar na área. Porém uma pequena parcela delas, que se consegue manter ao longo do tempo, demonstra produtividade maior que a dos homens. Isso porque, das poucas mulheres fotojornalistas encontradas, cerca de 21\% dos profissionais, apenas 21, que atuam, no total, em 23 agências, são responsáveis por $70 \%$ da produção feminina. Destas, duas delas, sozinhas, respondem por, praticamente, metade das coberturas femininas do período. Somada a isso, a comparação entre a quantidade de agências em que um mesmo profissional atuou, indica que as mulheres podem receber menos oportunidades de colocação que os homens.

Apesar da pouca ocupação feminina no fotojornalismo, a análise do portal Fotos Públicas aponta indícios, na tabela 1, de um aumento de 42,1\% do acumulado da produção feminina ao longo do tempo, número que quase se equipara ao aumento do acumulado da produção masculina, que foi de 44,7\% no mesmo período, mesmo que em menor quantidade de pautas cobertas. Os números podem sugerir que as mulheres ativas na área se vêm apropriando mais desse espaço conquistado, com a possibilidade de auxiliar a quebra do estereótipo de que o fotojornalismo não seja uma atividade também feminina. Mesmo que o processo de mudanças nas matrizes de percepção de valores sociais seja lento e gradual, ele demonstra que é possível, às mulheres, ocupar, com propriedade, o fotojornalismo e quebrar estereótipos entre os colegas e os empregadores. 


\section{CONSIDERACOOES FINAIS}

Este trabalho propôs-se a levantar indícios quantitativos sobre a atuação de fotojornalistas dentro da realidade da fotografia de distribuição gratuita, por meio da análise do portal Fotos Públicas. A partir dos dados capturados e analisados sobre o portal, pudemos realizar três enfoques principais: a respeito da produtividade de seus profissionais, da atuação nas agências identificadas e da cobertura dentro das editorias, levando, em consideração, o recorte de gênero. Por meio desse levantamento, buscamos traçar um perfil médio sobre os profissionais identificados e refletir sobre os diferentes valores sociais atribuídos aos gêneros, segundo a economia de trocas simbólicas, de Pierre Bourdieu.

A análise, de pouco mais de dois anos do portal, encontrou 1.301 profissionais, entre eles 261 mulheres e 1.040 homens. No âmbito geral dos fotojornalistas, o perfil seria o de um homem, que atua em uma agência pública e em até mais duas agências, na cobertura de Política. Por outro lado, ao olhar o enfoque feminino, o retrato seria de uma mulher, que atua, provavelmente, em uma agência pública e em até mais uma agência, na cobertura de Cotidiano.

Em última análise, faz-se necessário ressaltar que somente um trabalho quantitativo não é capaz de responder a todas as questões sobre a complexa realidade da atuação dentro do mercado fotojornalístico. Seria necessário consultar os profissionais envolvidos para tentar elucidar as motivações por trás dos números. Entretanto os dados disponibilizados podem ser utilizados como estímulo a futuras pesquisas na área.

\section{REFERÊNCIAS}

BERGAMO, Alexandre; MICK, Jacques (Coord.); LIMA, Samuel. Quem é o jornalista brasileiro? Perfil da profissão no país. UFSC/FENAJ, 2012. Disponível em: < http://www.fenaj.org.br/relinstitu/ pesquisa_perfil_jornalista_brasileiro.pdf>. Acesso em: 6 ago. 2015.

BOURDIEU, Pierre. A dominação masculina. Tradução de Maria Helena Kühner. Rio de Janeiro: BestBolso, 2. ed., 2014.

HANDLAND, Adrian, CAMPBELL, David, LAMBERT, Paul. The State of News Photography:be Lives and Livelihoods of Photojournalists in the Digital Age. [s.1.]: University of Oxford, Reuters Institute for the Study of Journalism, 2015. Disponível em: <http://reutersinstitute.politics.ox.ac.uk/sites/ default/files/The $\% 20$ State $\% 20$ of $\% 20$ News $\% 20$ Photography.pdf>. Acesso em: 25 set. 2015.

LIPPIMANN, Walter. Estereótipos. In: Opinião pública. Tradução de Jacques A. Wainberg. Petrópolis: Vozes, 2008. p. $96-111$.

SOUZA, Jorge Pedro. Uma história crítica do fotojornalismo ocidental. Chapecó: Argos: Florianópolis: Letras Contemporâneas, 2004. 255 p.

TEMER, Ana Carolina; ASSIS, Francisco de; SANTOS, Marli dos. Mulheres jornalistas e a prática do jornalismo de imersão: por um olhar sem preconceito. Media\&Jornalismo. n. 25, v. 14, n. 2, out./inv., 2014. Disponível em: <http://cimj.org/revista/25/AnaTFranciscoAMarliS.pdf >. Acesso em: 4 dez. 2015. 